\title{
Pengaruh Pektin Buah Apel (Malus Sylvestris Mill) Terhadap Kadar LDL Kolesterol pada Tikus Putih Jantan (Rattus Novergicus) Hiperkolesterolemia
}

\author{
Zurni Nurman ${ }^{1}$, Masrul $^{2}$, Susila Sastri ${ }^{3}$
}

\begin{abstract}
Abstrak
Hiperkolesterolemia dapat dikurangi dengan meningkatkan ekskresi kolesterol melalui cairan empedu. Pektin, dapat mengikat cairan empedu sehingga asam empedu yang kembali ke hati lebih sedikit, sehingga kolesterol darah akan menurun. Tujuan penelitian ini adalah untuk mengetahui pengaruh pektin buah apel terhadap kadar LDL tikus hiperkolesterolemia. Penelitian ini adalah experimental dengan the post test only control group design. Sampel adalah 25 ekor tikus, dibagi menjadi 5 kelompok perlakuan yaitu kelompok kontrol negatif (KN) dan kontrol positif (KP), perlakuan P1, P2, dan P3, masing-masing diberikan diet tinggi lemak sapi dan pektin dengan dosis 90, 180 dan 360 mg. Data dianalisis dengan uji paired sample $t$ test dan perbedaan LDL kolesterol antara kelompok penelitian dengan Anova. Hasil penelitian menunjukkan rata-rata LDL pada tikus hiperkolesterolmia sebelum perlakuan yaitu $\mathrm{KN}: 2,08 \pm 0,65, \mathrm{KP}: 2,79 \pm 1,26, \mathrm{P} 1: 3,45 \pm 0,75, \mathrm{P} 2: 2,76 \pm 0,39$, dan $\mathrm{P} 3: 3,21 \pm 1,04$. Rata-rata LDL tikus hiperkolesterolmia setelah perlakuan pada $\mathrm{KN}: 1,96 \pm 0,85, \mathrm{KP}: 2,96 \pm 0,52, \mathrm{P} 1: 2,00 \pm 1,42, \mathrm{P} 2: 1,19 \pm 0,28$ dan $\mathrm{P} 3: 2,19 \pm 0,53$. Terdapat perbedaan signifikan antara LDL darah tikus hiperkolesterolemia sebelum dan setelah diberikan pektin pada P2 dan P3 $(p<0,05)$. Terdapat perbedaan signifikan LDL setelah perlakuan antara perlakuan dan kontrol $(P<0,05)$. Simpulan penelitian yaitu pemberian pektin $180 \mathrm{mg}$ menyebabkan penurunan kolesterol yang paling bermakna.
\end{abstract}

Kata kunci: Pektin, LDL, Hiperkkolesterolemia

\begin{abstract}
Hypercholesterolemia is a condition when the LDL in blood increases. Increasing the excretion of cholesterol through bile is one solution to stabilize LDL. Pectin can bind to the bile acid in order to limit the amount returning to the liver. As a result, more bile acid will be produced from blood cholesterol resulting in a cholesterol level decrease. The objective of this study was to investigates the effect of apple pectin on LDL level in rats with hypercholesterolemia. This was experimental research with the post test only control group design. The sample was 25 white male rats divided into 5 treatment groups; KN, KP, P1, P2, P3, fed a diet of dairy fat diet and pectin at doses of 90,180,360 mg respectively. Data were analyzed using a paired sample t-test and independent sample t-test was applied to observe the difference of $L D L$ cholesterol level among treatment groups. The result of the research shows that the average $L D L$ of hypercholesterolemia, before treatment were $K N: 2.08 \pm 0,65, K P: 2.79 \pm 1,26, P 1: 3.45 \pm 0,75, P 2: 2.76 \pm 0,39, P 3$ : $3,21 \pm 1,04$ and after treatment were at $K N: 1.96 \pm 0,85, K P: 2.96 \pm 0,52, P 1: 2.00 \pm 1,42, P 2: 1.19 \pm 0,28, P 3: 2.19 \pm 0,53$. There was a significant difference between $L D L$ blood rats with hypercholesterolemia before and after being fed with pectin in groups $P 2$ and $P 3(p<0.05)$. There was a significant difference in $L D L$ after therapy between treatment and control group $(P<0.05)$. The conclusion of research is $180 \mathrm{mg}$ of apple pectin is sufficient to reduce the $L D L$ cholesterol level in rats.
\end{abstract}

Keywords: pectin, LDL, hypercholesterolemia 
Affiliasi penulis: 1. Prodi S2 Biomedik FK Unand (Fakultas Kedokteran Universitas Andalas Padang). 2. Bagian IImu Gizi FK Unand. 3. Bagian Biokimia FK Unand

Korespondensi: Zurni Nurman Arial. Email: zurniriski@yahoo.co.id Hp: 081266591352

\section{PENDAHULUAN}

Hiperkolesterolemia merupakan suatu kondisi yang ditandai dengan meningkatnya kadar kolesterol total dan Low Density Lipoprotein (LDL) serta menurunkan High Density Lipoprotein (HDL) darah. ${ }^{1}$

Penyakit jantung koroner merupakan salah satu penyakit tidak menular dengan angka mortalitas yang cukup tinggi meluas di seluruh dunia dan semakin meningkat setiap tahunnya. Lebih dari 17 juta kematian global disebabkan oleh penyakit jantung setiap tahun, angka ini diperkirakan akan terus meningkat menjadi 23,6 juta angka kematian sampai tahun $2030 .^{2}$

Sejumlah penelitian menunjukkan hubungan positif antara diet serat larut air dengan penurunan risiko penyakit kardiovaskular melalui penuruan hiperkolesterolemia. Asupan serat larut 6 gram/hari dapat mengurangi LDL-kolesterol 5,4\% dan menurunkan risiko PJK 9\%. ${ }^{3}$ Setiap 10 gram serat yang ditambahkan ke diet, dapat menurunkan risiko kematian PJK sebesar $17-35 \%{ }^{4}$

Serat larut air yang berperan dalam menurunkan kolesterol darah adalah pektin. Pektin berperan menghambat reabsorpsi asam empedu sehingga kolesterol diekskresikan lebih banyak melalui feses. Sebagai kompensasi kolesterol hati akan meningkatkan produksi asam empedu, sehingga kolesterol darah (LDL kolesterol) akan menurun. ${ }^{3}$

Mekanisme penurunan kadar kolesterol oleh serat larut air seperti pektin dengan cara mengikat asam empedu. Asam empedu dari kolesterol diubah oleh hati menjadi asam empedu sehingga asam empedu yang balik melalui siklus enterohepatik berkurang dari normal dan ekskresi asam empedu meningkat. Homeostatis kolesterol oleh tubuh dengan cara mensintesis kolesterol dari bahan dasar (endogen) asetil Ko-A, apabila terus berlanjut akan menurunkan kolesterol darah melalui feses serta menurunkan sintesis kolesterol dalam hati. ${ }^{5}$

Beberapa penelitian tentang pektin terhadap penurunan kolesterol yaitu konsumsi 5 gram pektin setiap harinya, mampu menurunkan kadar kolesterol dalam darah. ${ }^{6}$ Penelitian lain menyebutkan bahwa konsumsi 9 gram pektin setiap hari mengurangi jumlah kolesterol darah. ${ }^{7}$ Pektin pada tanaman terdapat pada kulit dan daging buahnya. Seperempat bagian dari sebuah apel terdiri dari substansi yang dinamakan pectin. Kulit apel memiliki kandungan pektin yang lebih banyak dari daging buahnya. $^{8}$ Penelitian lain menyebutkan bagian daging apel mengandung pektin berkisar $15-20 \%$ berat apel dan pada kulit berkisar 4$7 \%$ berat apel. ${ }^{9}$

Masyarakat kita sering membuang kulit apel sebelum dikonsumsi, padahal kulit apel mengandung pektin yang berguna dalam menurunkan kolesterol darah. Buah apel Manalagi merupakan salah satu apel lokal dengan kandungan pektinnya sebesar 0,14$0,98 \%{ }^{10}$

Tujuan penelitian ini adalah untuk mengetahui pengaruh pektin buah apel (Malus Sylvestris Mill) terhadap kadar LDL-kolesterol pada tikus putih jantan (Rattus Novergicus) hiperkolesterolemia.

\section{METODE}

Penelitian ini merupakan studi eksperimental dengan desain pre-post test with control group. Populasi dan sampel dalam penelitian ini adalah tikus putih jantan jenis Rattus novergicus sebanyak 35 ekor. Kriteria inklusi adalah tikus putih jantan galur wistar, hidup dan berbadan sehat, umur 3-4 bulan, berat 200300 gr. Kriteria eksklusi adalah Selain tikus putih jantan galur wistar, tikus berusia lebih dari 4 bulan dan tikus sakit/mati selama penelitian. Penelitian ini dilaksanakan pada bulan Januari - Mei 2017.

Variabel dependen adalah kadar LDL kolesterol tikus hiperkolesterolemia. Pengukuran LDL kolesterol dilakukan dengan metode Cholesterol Oxidase Phenol Aminophenazone (CHOD-PAP) yang menggunakan kit LDL kolesterol untuk tikus dengan alat ukur spektofotometer. Hasil ukurnya didapatkan dengan satuan $\mu / \mathrm{mL}$. Variabel independen penelitian ini adalah pektin dengan dosis bertingkat yaitu 90 $\mathrm{mg} / \mathrm{hari}, 180 \mathrm{mg} /$ hari dan $360 \mathrm{mg} / \mathrm{hari}$.

Prosedur kerja penelitian yaitu pembuatan pektin(isolasi pektin). ${ }^{11}$ persiapan dan pemeliharaan hewan coba, pemberian diet tinggi lemak, perencanaan dosis, perlakuan pada hewan coba, dan 
pengambilan darah tikus. Analisis data diuji secara statistik dan dilakukan uji normalitas Sphiro Wilk untuk melihat data terdistribusi normal atau tidak. Untuk melihat pengaruh pemberian pektin buah apel dengan dosis 90, 180 dan $360 \mathrm{mg} /$ hari dilakukan uji paired sampel $t$ test. Perbedaan kadar LDL kolesterol antara tikus yang diberi pektin buah apel dengan dosis 90 , 180 dan $360 \mathrm{mg} / \mathrm{hari}$ dilakukan uji ANOVA dengan derajat kepercayaan 95\%. Hasil yang didapat bila bermakna pada kelompok perlakuan $(p<0,05)$ maka akan dilanjutkan dengan uji statistik Multiple Comparison (Post Hoc Post) jenis Bonferroni.

HASIL

Sampel sebanyak 35 ekor tikus terbagi dalam 5 kelompok yaitu kelompok kontrol negatif (KN), kontrol positif (KP) dan 3 kelompok perlakuan yaitu perlakuan 1 (P1) pektin dosis $90 \mathrm{mg}$, perlakuan 2 (P2) pektin dosis $180 \mathrm{mg}$ dan perlakuan 3 (P3) pektin dosis 360 mg. Masing-masing kelompok terdiri dari 7 ekor tikus.

Selama penelitian, 7 ekor tikus mati, tersisa 28 ekor, dengan mempertimbangkan rumus sampel, menjadi 25 ekor (5 ekor ditiap kelompoknya). Sebelum perlakuan, tikus diberikan lemak sapi $2 \mathrm{~m} / 200 \mathrm{grBB}$ tikushari, agar tikus hiperkolesterolemia. Kelompok yang diberi lemak sapi adalah kelompok KP,P1,P2 dan P3. Setelah tikus hiperkolesterolemia, diberikan pektin sesuai dosis.

Tabel 1. Distribusi sampel berdasarkan kadar LDL kolesterol setelah diinduksi lemak sapi (sebelum diberi pektin)

\begin{tabular}{cccc}
\hline Variabel & Rerata \pm SD & Min & Mak \\
\hline KN & $2,08 \pm 0,65$ & 1,21 & 2,70 \\
KP & $2,79 \pm 1,26$ & 1,02 & 4,30 \\
P1 & $3,45 \pm 0,75$ & 2,72 & 4,35 \\
P2 & $2,76 \pm 0,39$ & 2,28 & 3,21 \\
P3 & $3,21 \pm 1,04$ & 2,51 & 5,04 \\
\hline
\end{tabular}

Tabel 1. menunjukkan kadar kolesterol pada $K P, P 1, P 2$, dan $P 3$ lebih tinggi dari $K N$. Hal ini menunjukkan setelah di induksi lemak sapi pada KP, P1, P2, dan P3 terjadi peningkatan kadar kolesterol darah.
Tabel 2. Distribusi sampel berdasarkan kadar LDL kolesterol setelah diberi perlakuan

\begin{tabular}{cccc}
\hline Variabel & Mean \pm SD & Min & Mak \\
\hline KN & $1,97 \pm 0,85$ & 1,03 & 3,28 \\
KP & $2,96 \pm 0,52$ & 2,12 & 3,55 \\
P1 & $2,00 \pm 1,42$ & 0,86 & 4,40 \\
P2 & $1,19 \pm 0,28$ & 1,01 & 1,68 \\
P3 & $2,19 \pm 0,53$ & 1,58 & 2,97 \\
\hline
\end{tabular}

Tabel 2 dapat dilihat setelah diberikan lemak sapi selama 18 hari dan pektin 15 hari terdapat penurunan pada $\mathrm{P} 1, \mathrm{P} 2$ dan $\mathrm{P} 3$, penurunan yang paling banyak pada $\mathrm{P} 2$.

Tabel 3. Perbedaan rata-rata kadar LDL kolesterol sebelum dan setelah perlakuan

\begin{tabular}{cccccc}
\hline \multirow{2}{*}{ Kelompok } & \multicolumn{2}{c}{ Kadar LDL $(\boldsymbol{\mu g} / \mathrm{mL})$} & & \\
\cline { 2 - 4 } & $\begin{array}{c}\text { Sebelum } \\
\text { Mean } \pm \text { SD }\end{array}$ & $\begin{array}{c}\text { Sesudah } \\
\text { Mean } \pm \text { SD }\end{array}$ & & $\mathbf{p}$ \\
\hline KN & $2,08 \pm 0,65$ & $1,97 \pm 0,85$ & 5 & 0,71 \\
KP & $2,79 \pm 1,26$ & $2,96 \pm 0,52$ & 5 & 0,66 \\
P1 & $3,45 \pm 0,75$ & $2,00 \pm 1,42$ & 5 & 0,13 \\
P2 & $2,76 \pm 0,39$ & $1,19 \pm 0,28$ & 5 & 0,00 \\
P3 & $3,21 \pm 1,04$ & $2,19 \pm 0,53$ & 5 & 0,03 \\
\hline
\end{tabular}

Tabel 3 menggambarkan kadar LDL-kolesterol darah tikus mengalami penurunan setelah diberikan pektin pada semua kelompok penelitian. Setelah diuji secara statistik hanya kadar LDL-kolesterol P2 dan P3 yang ada perbedaan signifikan $(p<0,05)$ antara sebelum dan setelah pemberian pektin. Hal ini berarti ada pengaruh pemberian pektin dosis $180 \mathrm{mg}$ dan 360 mg terhadap penurunan kadar LDL-kolesterol darah tikus.

Tabel 4. Perbedaan rata-rata kadar LDL kolesterol setelah perlakuan antara tiap kelompok

\begin{tabular}{cccc}
\hline Variabel & $\begin{array}{c}\text { Kadar LDL Darah } \\
(\boldsymbol{\mu g} / \mathbf{m L}) \\
(\text { Mean } \pm \text { SD })\end{array}$ & $\mathbf{n}$ & $\mathbf{p}$ \\
\hline KN & $1,97 \pm 0,85$ & 5 & \\
KP & $2,96 \pm 0,52$ & 5 & \\
P1 & $1,99 \pm 1,42$ & 5 & 0,04 \\
P2 & $1,19 \pm 0,28$ & 5 & \\
P3 & $2,19 \pm 0,53$ & 5 & \\
\hline
\end{tabular}


Pada Tabel 4 diketahui rerata kadar LDLkolesterol darah setelah perlakuan antara kelompok dan hasil uji statistik didapatkan nilai $p<0,05$ yang berarti pada alpha $5 \%$ dapat disimpulkan ada perbedaan rerata kadar LDL-kolesterol darah antara kelima kelompok tikus percobaan. Untuk melihat perbedaan rata-rata LDL-kolesterol antara masingmasing kelompok dilanjutkan uji Post Hoc Test Multiple Comparisons, jenis Bonferoni.

\section{PEMBAHASAN}

Kadar LDL kolesterol setelah diinduksi lemak sapi (sebelum diberi pektin)

Hasil penelitian setelah diinduksi lemak sapi selama 18 hari terdapat peningkatan kadar kolesterol darah tikus (hiperkolesterolemia). Hasil penelitian ini sejalan dengan penelitian yang dilakukan oleh Susanti yang membuktikan bahwa pemberian lemak sapi selama 18 hari melalui sonde dapat meningkatkan kadar kolesterol darah. ${ }^{12}$ Hasil ini juga sesuai dengan yang didapatkan Harsa menyimpulkan bahwa dengan pemberian diet tinggi lemak dapat meningkatkan kolesterol total, trigliserida dan LDL-kolesterol darah tikus. ${ }^{13}$ Pemberian lemak sapi dapat meningkatkan kadar kolesterol dalam low density lipoprotein (LDL) tikus jantan. ${ }^{14}$

Lemak terbanyak yang terdapat dalam diet adalah lemak netral yang dikenal sebagai trigliserida. Lemak netral merupakan unsur utama dalam bahan makanan yang berasal dari hewan, dan sedikit saja yang terdapat dalam tumbuhan. ${ }^{15}$

Pemberian diet tinggi lemak akan menyebabkan peningkatan konsentrasi kilomikron dalam plasma sebesar 1-2 persen dari total plasma dalam waktu satu jam setelah makana. ${ }^{16}$ Kilomikron disintesis dalam mukosa usus selama proses penyerapan produk pencernaan lemak. Kilomikron memiliki fungsi yang sangat penting dalam mengangkut lipid yang terbentuk dari proses pencernaan dan penyerapan menuju ke hati. ${ }^{15}$ Hasil ini sesuai dengan Nair dan Goldstein yang menyimpulkan bahwa asupan lemak jenuh yang tinggi dikaitkan dengan peningkatan produksi LDL-kolesterol dan turunnya aktivitas reseptor LDL-kolesterol. ${ }^{17}$
Peningkatan kadar kolesterol dalam darah dapat disebabkan oleh tiga hal yaitu diet yang terlalu banyak mengandung kolesterol sehingga tubuh tidak mampu untuk mengendalikannya, ekskresi kolesterol ke kolon melalui empedu terlalu sedikit dan produksi kolesterol dalam hati terlalu banyak. ${ }^{18}$

Makanan yang mengandung lemak jenuh memiliki pengaruh hiperkolesterolemik disebabkan penekanan aktivitas reseptor LDL dalam sel-sel hati dan meningkatkan apolipoprotein (apo) B yang menyebabkan produksi lipoprotein sehingga terjadi peningkatan kadar kolesterol LDL dalam darah. Dampak dari kelebihan kolesterol dapat dikurangi dengan melakukan perubahan gaya hidup seperti berhenti merokok, minuman beralkohol, berolahraga yang teratur dan makan makanan dengan komposisi yang baik. $^{18}$

\section{Kadar LDL kolesterol setelah diberikan Pektin}

Hasil penelitian ini menemukan bahwa rerata kadar LDL-kolesterol darah tikus kontrol negatif $(\mathrm{KN})$ lebih rendah dari kelompok tikus kontrol positif (KP), dan kelompok kontrol positif lebih tinggi dari kelompok P1, P2 dan P3. Hal ini disebabkan karena pada kelompok perlakuan diberikan pektin dan kelompok kontrol positif tidak diberikan pektin. Hasil ini sesuai dengan penelitian yang dilakukan pada binatang dan dsimpulkan bahwa terdapat penurunan kadar LDL kolesterol setelah diberikan diet apel. ${ }^{19}$

Pektin bersifat mengikat dan meningkatkan pengeluaran asam empedu yang kemudian akan terbuang bersama-sama feses. Pengikatan asam empedu oleh pektin menyebabkan asam empedu keluar dari siklus enterohepatik. Penurunan jumlah asam empedu menyebabkan hepar menggunakan kolesterol dalam darah sebagai bahan untuk membentuk asam empedu baru. Peningkatan asam empedu feses atau kolesterol yang hilang dapat menyebabkan penurunan kolesterol plasma, dan meningkatkan biosintesis turnover kolesterol pada hewan coba. ${ }^{20}$ Pada kelompok kontrol positif tidak ada serat pektin yang akan mengikat asam empedu sehingga tidak terjadi eliminasi asam empedu melalui feses. 
Perbedaan rerata kadar LDL kolesterol tikus sebelum dan setelah diberikan pektin

Berdasarkan hasil penelitian didapatkan bahwa terdapat penurunan rerata kadar LDLkolesterol darah tikus sebelum dan setelah pemberian pektin di semua kelompok penelitian. Setelah diuji secara statistik didapatkan P2 dan P3 terdapat perbedaan signifikan antara sebelum dan setelah pemberian pektin dosis $180 \mathrm{mg}$ dan $360 \mathrm{mg}(p<0,05)$. Setiap orang yang mengonsumsi 5 gram pektin setiap harinya, mampu menurunkan kadar kolesterol dalam darah. ${ }^{6}$

Kecenderungan ini disebabkan karena pektin dapat mengubah proporsi asam empedu yang dikembalikan ke hati yaitu dengan cara mengikat asam empedu, dengan menurunnya kadar asam empedu hati akan membentuk asam empedu baru dari kolesterol yang diambil dari dalam darah. Mekanisme tersebut menyebabkan kolesterol dalam darah darah akan menurun. Hal tersebut juga sependapat dengan hasil penelitian yang menyimpulkan pemberian pektin 15 gram setiap hari mengakibatkan pengurangan 15\% rata-rata kadar kolesterol plasma. ${ }^{21}$

Pada penelitian ini didapatkan semakin tinggi kadar pektin yang diberikan maka semakin berpotensi menurunkan kadar LDL-kolesterol darah tikus. Hal ini membuktikan bahwa semakin tinggi dosis pektin maka semakin optimal kemampuannya dalam mengikat asam empedu yang merupakan hasil akhir metabolisme kolesterol, makin banyak asam empedu yang berikatan dengan pektin dan terbuang keseluruh tubuh makin banyak kolesterol yang di metabolisme, sehinga pada akhirnya kolesterol menurun jumlahnya. ${ }^{5}$

\section{Perbedaan rerata kadar LDL kolesterol tikus pada berbagai kelompok penelitian.}

Kadar LDL-kolesterol setelah penelitian pada kelompok $\mathrm{KN}$ lebih rendah dari pada kelompok KP. Sedangkan kelompok P1, P2, P3 memiliki kadar LDLkolesterol juga lebih rendah dari pada kelompok KP. Setelah diuji secara statistik didapatkan ada perbedaan signifikan rata-rata kadar LDL-kolesterol dalam darah tikus di berbagai kelompok penelitian. Hiperkolesterolemia menyebabkan peningkatan kadar LDL-kolesterol dalm darah yaitu sebagai lipoprotein pengangkut kolesterol terbesar dalam tubuh. Pada kelompok KP ditemukan kadar LDL-kolesterol paling tinggi setelah proses penelitian. Hal ini disebabkan karena pemberian pakan yang ditambahkan dengan lemak sapi mampu meningkatkan kadar LDLkolesterol darah tikus.

Adanya perbedaan rerata kadar LDL-kolesterol diantara kelompok disebabkan karena pektin berpengaruh dalam menurunkan LDL-kolesterol. Pektin diharapkan dapat membantu penurunan kadar LDL-kolesterol pada penderita hiperkolesterolemia dengan dosis yang tepat. Dosis $360 \mathrm{mg}$ pada tikus hiperkolesterolemia dalam penelitian ini merupakan dosis maksimal yang mampu menurunkan kadar LDLkolesterol, namun yang paling memberikan efek terhadap penurunan kadar LDL-kolesterol adalah dosis $180 \mathrm{mg}$. Hal ini terbukti dengan uji Post Hoc Test Bonferroni yang menemukan perbedaan yang signifikan antara KP dengan $\mathrm{P} 2$, yang menunjukkan bahwa pemberian pektin dengan dosis 2 yaitu $180 \mathrm{mg}$ sudah memberikan pengaruh terhadap kadar LDLkolesterol.

Hasil kadar LDL-kolesterol antara dosis P2 lebih rendah dari $\mathrm{P} 1$ dan $\mathrm{P} 3$, namun berdasarkan uji Post Hoc Test tidak terdapat perbedaan kadar LDLkolesterol antara dosis kelompok P1, P2, dan P3 $(p>0,05)$. Hal tersebut dapat disebabkan oleh adanya variasi efek biologis pemberian lemak sapi dan pektin pada hewan coba yang diberikan melalui sonde, ketidaknyamanan, iritasi atau stress yang dialami tikus dapat mempengaruhi kadar LDL-kolesterol.

\section{SIMPULAN}

Terdapat perbedaan yang signifikan antara kadar LDL-kolesterol tikus hiperkolesterolemia sebelum dan setelah diberikan pektin pada kelompok perlakuan dua dan kelompok perlakuan tiga.

Terdapat perbedaan rerata kadar LDLkolesterol tikus setelah penelitian di antara berbagai kelompok penelitian, dimana kelompok yang bermakna adalah kelompok kontrol positif dan kelompok perlakuan dua.

Dosis $180 \mathrm{mg}$ merupakan dosis pektin yang paling berpengaruh terhadap penurunan kadar LDLkolesterol tikus hiperkolesterolemia. 


\section{SARAN}

Hasil penelitian ini membuktikan bahwa pektin buah apel mampu menurunkan LDL-kolesterol sehingga perlu dilakukan penelitian lebih lanjut pemberian pektin buah apel pada manusia. Perlu dilakukan penelitian lebih lanjut untuk melihat pengaruh apel utuh terhadap penurunan LDLkolesterol pada tikus hiperkolesterolemia.

\section{UCAPAN TERIMAKASIH}

Terima kasih buat semua pihak yang telah membantu dalam penelitian ini.

\section{DAFTAR PUSTAKA}

1. Arisman. Obesitas, diabetes melitus \& dislipidemia. Jakarta: EGC; 2010.

2. Wong ND. Epidemiological studies of $\mathrm{CHD}$ and the evolution of preventive cardiology. Cardiol. 2014; 11:276-89.

3. Anderson JW, Baird P, Davis RH, Ferreri S, Knudtson M, Koraym A, et al. Health benefits of dietary fiber. Nutr. Rev. 2009;67(4):188-205.

4. Otles S, Ozgoz S. Health effects of dietary fiber. Acta Sci. Pol. Technol. Aliment. 2014;13(2):191202.

5. Theuwissen E, Mensink RP. Viscous soluble fibers and cardiovascular disease. In: The role of $\beta$-glukan, plant stanols, and oxy(phyto)sterols in managing cardiovascular risk. Physiol Behav. 2008;94:285-92.

6. Srivastava P, Malviya R. Sources of pectin, extraction and its application in pharmaceutical industry-An overview. Indian Journal of Natural Products and Resources. 2011;2:10-8.

7. Mills KE, Mackerras D. Does daily consumption of pectin lower cholesterol concentration? A systematic review and meta analysis. $\mathrm{J}$ or Nutrition \& Intermediary Metabolism. 2016:6-47.

8. Boyer J, Liu RH. Apple phytochemicals and their health benefits. Nutrition Journal. 2014;3(5):1-15.

9. Subagyo $P$, Achmad Z. Pemungutan pektin dari kulit dan ampas apel secara ekstraksi. EKSERGI. Jurnal IImiah Jurusan Teknik Kimia. 2010;10(2): 47-51.
10. Abidah N, Dewanti TW, Ida NP, Dita S, Wijayanti, Mahar JM. Pengaruh margarin apel manalagi tersuplementasi minyak kacang tanah terhadap kadar kolesterol tikus Spragus dawley jantan. Jurnal Pangan dan Agroindustri. 2014;2(1):18-27.

11. Sulihono A, Tarihoran B, Agustina TE. Pengaruh waktu, temperatur dan jenis pelarut terhadap ekstraksi pektin dari kulit jeruk bali (Citrus maxima). Jurnal Teknik Kimia. 2012;18(4):1-8.

12. Susanti. Pengaruh jus lidah buaya terhadap profil lipid tikus putih jantan hiperlipidemia (tesis). Padang: Fakultas Kedokteran Universitas Andalas; 2014.

13. Harsa MS. Efek pemberian diet tinggi lemak terhadap profil lemak darah tikus putih (Rattus norvegicus). Jurnal "Ilmiah Kedokteran". 2014;3(1): 21-8.

14. Sihombing SF. Efek pemberian diet tinggi lemak terhadap kadar LDL dan ketebalan dinding aorta tikus jantan (tesis). Padang: Fakultas Kedokteran Universitas Andalas; 2014.

15. Mayes PA. Sintesis, pengangkutan dan ekskresi kolesterol. Dalam: Murray RK, Graner DK, Mayes PA, Rodwel VW, editor (penyunting). Biokimia Harper. Penerjemah; Manurung, Lilian R, Mandera, Lydia I. Jakarta: EGC; 2009. hIm.279-90.

16. Mark DB. Metabolisme Kolesterol dan lipoprotein darah. Dalam: Marks DB, Allan D, Smith CM. Biokimia Kedokteran Dasar: Sebuah Pendekatan Klinis, Penerjemah; Suryono J, Sadikin V, Lidya I, Mandera. Jakarta: EGC. 2012.

17. Nair P. Brown, Goldstein: The cholesterol chronicles. 2013;110(37):14829-832.

18. Mumpuni Y. Cara jitu mengatasi kolesterol. Jakarta: Andi. 2011.

19. Jones JM. Dietary fiber future directions: integrating new definition and finding to inform nutrition research and communicationl. Adv. Nutr. 2013;4:8-15.

20. Cai JS, Chen JH. The mechanism of enterohepatic circulation in the formation of gallstone disease. $\mathrm{J}$ Membrane Biol. 2014;247:1067-82.

21. Sharma BR, Naresh L, Dhuldhoya NC, Merchant SU, Merchant UC. An overview on pectins. Times Food Processing Journal. 2016;44-51. 